\title{
Regional policies for sustainability in the Mediterranean countries: the role of a proper HVAC system maintenance in museums
}

\author{
Alessandra Galatioto $^{1, a}$, Salvatore Pitruzzella $a^{2, b}$, Gianluca Scaccianoce ${ }^{1, c}$, \\ Daniele Milone $e^{1, d}$
}

\author{
${ }^{1}$ Dipartimento dell'Energia, Università degli Studi Palermo, Viale delle Scienze 9, Palermo, ITALY \\ ${ }^{2}$ Facoltà di Architettura, Università degli Studi Palermo, Viale delle Scienze 14, Palermo, ITALY \\ a alessandra.galatioto@dream.unipa.it, ${ }^{b}$ pitruzzella@architettura.unipa.it, \\ c gianluca.scaccianoce@ unipa.it, 'cdaniele.milone@ unipa.it
}

Keywords: sustainability and museum, cultural heritage, risk indices, HVAC system maintenance.

\begin{abstract}
Italy, like several Mediterranean countries, holds a very large number of cultural artifacts that are often exhibited and saved inside museums. Museums are usually part of historical buildings that, not rarely, originally had a different intended use and that have been currently transformed in place for conservation and for exhibition of works of art. The use of historical buildings as museums leads to limitations in the management and distribution of exhibition space, in design and managing HVAC systems and in the achievement of targets relating to the continuous monitoring of the microclimate for people comfort and for preservation of works of art. Moreover, the costs of the operation and maintenance of the HVAC system for this particular type of confined environment are often very expensive and the proper optimization of the required operations plays a main role. In this paper, authors propose a new decision support tool for curators regarding the operation and maintenance management of HVAC systems in museums especially in the case of their belonging to cultural heritage buildings.
\end{abstract}

\section{Introduction}

Interactions between the museum and the outside environment, when not properly controlled, may accelerate the processes of deterioration, often irreversible, of both the building envelope itself and the works of art within it [1]. Provided that targets are achieved, it is necessary to implement a policy of sustainability in the management of cultural heritage and environment in order of preserving them, especially in the Mediterranean area, where the climatic conditions are potentially dangerous to a more rapid deterioration of works of art. The summer period is the time of increased turnout of people in museums; then, considering the outdoor air temperature, the indoor environment is often subjected to high heat load. This thermal load has to be subtracted by HVAC system, whose fault conditions or maintenance operations could lead to a risk condition for preserving works of art and, in turn, a socio-economic loss. Anyway, even in mild climate Mediterranean countries, outdoor winter conditions, particularly referring to the high values of relative/absolute air humidity, could result in severe risk conditions for the correct preservation of works of art. In other words, it is very important taking into accounts and avoiding conflicts among yearly budget available for maintenance, effectiveness (preservation of works of art and people comfort conditions), durability and energy saving. On this topic, it is very important the correct coping with the in force contracts of Operation and Maintenance Service, which have to outsource the maintain operations by also limiting the time of fault conditions, in order of avoiding "... pay the bill when they fail to respond to an emergency within the agreed-on time period ..." $[2,3]$. This work could support curators in the drafting of contract with regard to assessment of the property's damage and economic loss caused by a non-working occurrence of the HVAC system by means of the use of the simple of indicators here reported. The Italian standards [4] suggest proper environment conditions for each type of item exhibited in museums, although the same standards assert that museum curator must take the final 
decision about the environmental conditions for each item, because the values of the more suitable indoor physical parameters mainly derive from the history of item's environmental conditions which are usually well known to the curator. Therefore, it is very important an appropriate design and management of heating, ventilating and air conditioning systems, with the aim of getting the HVAC system to be very reliable.

\section{Microclimatic requirements in museums}

Microclimate for cultural heritage needs a particular care due to the enormous variety of the works of art exhibited in museums, to the different materials, which compose the cultural artefacts, and to the importance of these artefacts that are often unique in the world. Microclimate, in fact, plays a fundamental role in the degradation process of materials. In fact, the various parts constituting a given piece could be differently affected by the values of microclimate parameters and by their time and space changes. For example, sudden time changes and intense space variations of air temperature and relative humidity are supposed to induce inside stresses to several artefacts: this, in turn, could create cumulative and irreversible alterations of the chemical and physical properties that could accelerate the degradation process. Rather, generally speaking, any environmental perturbation contributes to the degradation process of the works of art. For these reasons, it would be extremely important the availability of technical standards and regulations for assessing the optimal values of the physical parameters in the exhibition spaces [5,6,7]. Many studies, worldwide, have been done in the aim of assessing the optimal features of the indoor climate of museums, with a particular attention to the deterioration of materials. Particularly, some Italian standards will be here mainly taken into account referring to the thermal-hygrometer conditions. These standards, in fact, suggest optimal values for the indoor parameters that, with minor differences, are in accordance with the most international standards. From the above, HVAC systems obviously play a key role regarding the control of environmental indoor conditions, particularly with respect to air temperature, relative air humidity and air quality management. Some aspects that influence HVAC system choice are maintenance access and risk of the collection disruptions due to leaks from overhead or decentralized equipment and from water or steam pipes over and within collection areas. Generally, in order to reach the design goals, all-air conditioning systems are preferred: a centralized air-handling unit keeps equipment, maintenance and monitoring at appropriate distance from the collections. Recently published ASHRAE studies [8] about the museums specify five possible control classes as regards the values and admitted fluctuations of the thermal-hygrometric parameters. The strictest classes (AA and A) provide a $\mathrm{RH}$ daily fluctuation lower than $\pm 5 \%$ around the set point value, while larger ranges are admitted in the case of chemically stable collections (classes B, C, D).

\section{Risk indicators for museums}

Some indicators reported in literature are described in detail; such indicators attempt to calculate or, at least, to estimate the probable damaging risk in connection with assigned environmental conditions with respect to pre-set reference values. Obviously, these may aid in the financial/economic loss assessments as a result of disservices of the HVAC system. Performance Index (PI). The Performance Index was proposed by Corgnati et al., and it is defined as a percentage of time when the measured parameter lies within the recommended/required tolerance interval. Moreover, the more important introduction by Corgnati and Filippi [9] is the definition of "warning limits" that should be set up according to the exhibition curators, e.g. they were fixed equal to $90 \%$ for $\mathrm{T}$ and $\mathrm{RH}$ values in the case of the oil on canvas by "Duccio di Buoninsegna". Obviously, the PI used to verify that museum HVAC system was suitably designed to maintain the microclimatic conditions required for 
preservation of works of art, as suggest by an Italian standard UNI 10829. Time Weighting Preservation Index (TWPI). The "Preservation Index" [10], proposed by Image Permanence Institute (IPI), represents an evolution of the criteria of Donald Serbera's Isoperms. Although this index is based on a detailed study of the hydrolysis cellulose acetate reaction, IPI has proposed to use it as gauge of the combined effects of temperature and relative humidity of the storage/exhibition environments for works of art composed by organic materials [11]. The mathematical expression of the IPI formulation of reaction kinetics is:

$$
\text { lifetime }=\frac{e^{\frac{95220-134.9 \times[R H \%]}{8.314 \times T}}+0.0284 \times[R H \%]-28.023}{360} .
$$

To take into account the overall impact of temperature and relative humidity variations on the rate of chemical degradation of organic materials over time, IPI introduces the Time Weighting Preservation Index (TWPI) that maybe calculated as follows:

$$
T W P I_{n}=\frac{n \cdot T W P I_{n-1} \cdot \text { lifetime }_{n}}{\text { lifetime } \cdot(n-1)+T W P I_{n-1}}
$$

where $n$ is total number of time intervals for the given sample, TWPI ${ }_{n-1}$ is the value of TWPI after time interval $n-1$ and lifetime $_{n}$ is the lifetime calculated at time intervals $n$.

Indicator based on "kinetic theory approach". Brazzoli et al. [12] provides a suitable mathematical model to describing the degradation of a work of art due to the action of external agents. This model, based on "Kinetic Theory Approach", assumes that the state of the system is identified by a number of independent variables, each of them linked to a suitable probability distribution; in the same way, the action due to the outer environment is decomposed into a number of random variables. Therefore, a stochastic description is necessary to take into account the random fluctuations related to the state variables of the system. This model takes into account effects both of external actions and of internal interactions among its components.

\section{The case study}

With the aim to assess the effectiveness of the proposed approach, the "Museo Regionale of Messina" (Italy) is here analysed. This building (built-up in the year 1990) is located on the coastline of the town of Messina. The hall contains two cultural artefacts: two famous oil on canvas, the "Resurrezione di Lazzaro" and the "Adorazione dei pastori" (1609) by Caravaggio. The air temperature and air relative humidity of one hall of this museum have been monitored for a whole year in free-floating conditions. The hall of Caravaggio is composed by three external walls (West, East and the Southfacing one). The monitoring of the hall has been performed for a whole year in free-floating conditions (HVAC system not working). The sample rate was setup equal to four samples per hour, that was turned out into a sample per hour. In order to apply the proposed methodology to selected room, the survey was carried out when the works of art was not inside. In order to evaluate the incidence of HVAC not working situations on risk of degradation of works of art, in a given period, authors have been chosen to analyze the whole season as the analysis period. Obviously, in order to get more detailed results could be possible to choose a shorter period (month, week or day). With the aim to evaluate the thermal physics performance of building envelope, we hypothesized that the HVAC system is able to maintain the microclimate requirements during almost the whole year, except during the cooling season. In Figure 1 trends are shown of indoor air temperature in the "Caravaggio" hall regarding the case of not working HVAC system during the cooling season (June, July and August), along with the outdoor air 
temperature. In the graph are also represented the optimal range suggest by the Italian Standard UNI 10839 , concerning the oil on canvas works of art. We want to remark the recurrent overcoming of this parameter from the optimal range for the good preservation. Same studies was carried out for the analysis of the relative humidity.

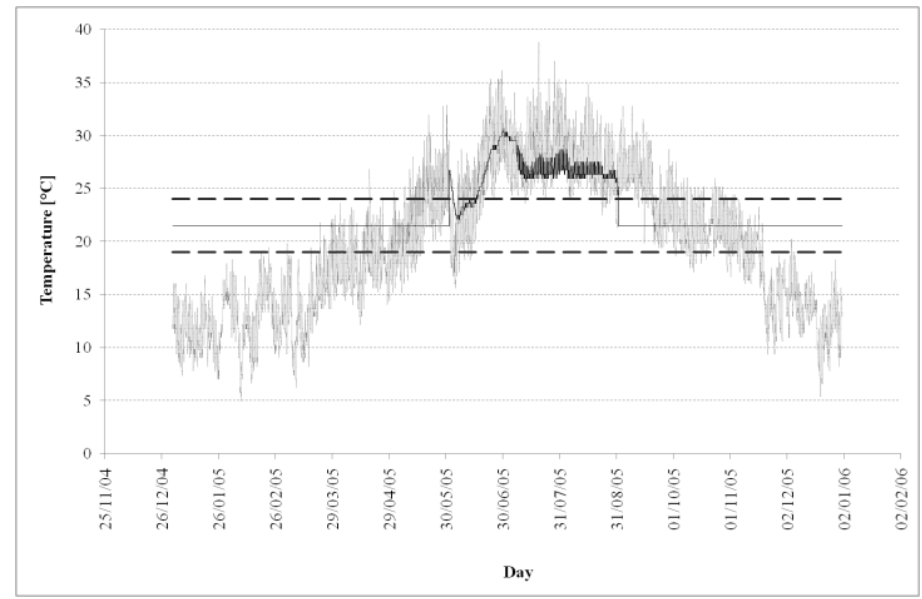

Figure 1. Hourly trend of the indoor and outdoor air temperature in the case of not-working HVAC system in the considered cooling season.

The trend of the indoor air temperature clearly shows that the building envelope is characterized by a low value of thermal inertia; this is not so strange, since the building here analysed is a new construction, instead of historical buildings, that often house museums in Italy.

In order to evaluate the degradation risk of works of art, in this case oil on canvas, the aforementioned indicators have been calculated and reported in the Table 1, both for the cooling and the heating seasons.

Table 1. Indoor conditions indicators in both "working" and "not working" conditions.

\begin{tabular}{l|c|c|l}
\hline Caravaggio hall & Working & $\begin{array}{c}\text { Not working } \\
\text { (June-July- Aug) }\end{array}$ & $\begin{array}{l}\text { Not working } \\
\text { (Dec-Jan-Feb-Mar) }\end{array}$ \\
\hline PI (t) & $100.0 \%$ & $77.9 \%$ & $68.9 \%$ \\
PI (rh) & $100.0 \%$ & $84.8 \%$ & $77.1 \%$ \\
PI (t-rh) & $100.0 \%$ & $77.3 \%$ & $68.5 \%$ \\
Kinetic Theory [years] & NA & 46 & 40.5 \\
TWPI (IPI) [years] & 40.2 & 29.3 & 45.3 \\
\hline
\end{tabular}

First three indicators, all referring to the Preservation Index, suggest performing the ordinary maintenance operations of HVAC system in the cooling season, as well as the indicator based on "kinetic theory approach". On the contrary, the TWPI suggests performing maintenance during the heating season; obviously this last result was easily predictable, since TWPI essentially considers that the more is the value of air temperature the more is the degradation of works of art.

With reference to first four indicators, the obtained results likely depend to relative air humidity values during the two analysed seasons, because they are considered the worst ones with respect to the limits value suggested by the Italian Standard.

In conclusion, a suitable combination of these indicators and of the methodology here described (free floating conditions analysis) is a viable tool for supporting decisions of curators regarding the operation and maintenance management. Moreover, a further development will involve an evaluation of the economic damage for works of art, due to a fault condition of HVAC system, with particular reference to riskier seasons (or shorter periods with highest risk). 


\section{Conclusion}

In museums, the HVAC system should be constantly operated for the correct conservation of the works of art and for the users thermal comfort. Thus, it is very important the suitable maintenance planning of the air-conditioning system, also in sight of the energy saving purposes that are usually a main concern of local administrators.

In this work, we have speculated about a new decision support tool for curators regarding the operation and maintenance management that mainly takes into account the preservation of works of art in museum buildings. This would help local administrations of Mediterranean countries in carrying out suitable policies for sustainability, effective actions for the energy saving, also taking in due count the enormous amount of cultural heritages belonging to this regional area.

\section{References}

[1] F. Ascione, L. Bellia, A. Capozzoli, F. Minichello. Energy saving strategies in air-conditioning for museums, Applied Thermal Engineering, 29 (2009) 676-686.

[2] PECI - Portland Energy Conservation Inc., Operation and Maintenance Service Contracts Guidelines for obtaining Best-Practice Contracts for Commercial Buildings, O\&M Best Practice Series, Portland, USA, 1997.

[3] G. P. Sullivan, R. Pugh, A. P. Melendez, W. D. Hunt, Operations \& Maintenance Best Practices A Guide to Achieving Operational Efficiency (Release 3), Pacific Northwest National Laboratory for the Federal Energy Management Program, U.S. Department of Energy, 2010.

[4] UNI 10829. Works of art of historical importance - Ambient conditions or the conservation Measurement and analysis, UNI-Ente Italiano di Unificazione, Milano, 1999. (in Italian)

[5] M. La Gennusa, F. Nicoletti, G. Rizzo, G. Scaccianoce, The control of indoor environment in heritage buildings: application of a methodology to an old Italian museum, J. Cult. Herit. 6 (2005) 147-155.

[6] M. La Gennusa., G. Rizzo, G. Rodonò, G. Scaccianoce, People comfort and artwork saving in museums: comparing indoor requisites, Int. J. Sustainable Design 1 (2009) 199-222.

[7] M. La Gennusa, G. Lascari, G. Rizzo, G. Scaccianoce, Conflicting needs of the thermal indoor environment of museums: In search of a practical compromise, Journal of Cultural Heritage 9 (2008) 125-134.

[8] ASHRAE Handbook-HVAC Applications. Chapter 21: Museums, Galleries, Archives, and Libraries. American Society of Heating, Refrigerating and Air-Conditioning Engineers inc., 2007

[9] S.P. Corgnati, M. Filippi, Assessment of thermo-hygrometric quality in museums: Method and in-field application to the "Duccio di Buoninsegna" exhibition at Santa Maria della Scala (Siena, Italy), Journal of Cultural Heritage 11(2010) 345-349.

[10] ASHRAE Handbook-HVAC Applications. Chapter 23: Museums, Galleries, Archives, and Libraries. American Society of Heating, Refrigerating and Air-Conditioning Engineers inc., 2011.

[11] J.M. Reilly, D.W. Nishimura, E. Zinn, New Tools for Preservation, assessing long-term environmental effects on library and archives collections, The Commission on Preservation and Access, Washington D.C., 1995.

[12] I. Brazzoli, S.P. Corgnati, M. Filippi, S. Viazzo, On the kinetic theory approach to modeling degradation phenomena in conservation sciences, J. Mathematical and Computer Modelling 45 (2007) 1201-1213. 